\title{
Acute effect of add-on therapy with tofogliflozin, a sodium glucose co-transporter 2 inhibitor, on 24-hour glucose profile and glycemic variability evaluated by continuous glucose monitoring in patients with type 2 diabetes receiving dipeptidyl peptidase-4 inhibitors.
}

\author{
Yoshimasa Aso ${ }^{1}$, Toshie Iijima ${ }^{1}$, Soichiro Hosonuma ${ }^{2}$, Hidetaka Kurai ${ }^{2}$, Hayato Kanitani ${ }^{2}$, \\ Shintaro Sakurai ${ }^{2}$, Takuya Tomaru², Teruo Jojima ${ }^{2}$, and Isao Usui ${ }^{2}$ \\ ${ }^{1}$ Dokkyo Medical University \\ ${ }^{2}$ Affiliation not available
}

June 2, 2021

\begin{abstract}
Aim: To investigate acute effects of add-on therapy with the sodium glucose co-transporter 2 inhibitor tofogliflozin to dipeptidyl peptidase (DPP)-4 inhibitors on 24-hour glucose profile and glycemic variability evaluated by continuous glucose monitoring (CGM) in patients with type 2 diabetes. Patients and methods: We studied 17 patients with type 2 diabetes who were hospitalized for glycemic control. CGM was performed for 7 consecutive days in the last week of hospitalization. Tofogliflozin $20 \mathrm{mg}$ /day was started on day 4 after initiating CGM and was administered to 10 patients receiving DPP-4 inhibitors and 7 patients not receiving DPP-4 inhibitors. We compared several CGM parameters between day 2 to 3 (ie, before treatment with tofogliflozin) and day 5 to 6 (ie, after starting treatment with tofogliflozin). Results: After starting treatment with tofogliflozin, mean 24-hour glucose and postprandial glucose after each meal were significantly decreased in both groups of patients. Time in range (ie, at a glucose level of $70-180 \mathrm{mg} / \mathrm{dL}$ ) was significantly increased in both groups. The standard deviation of 24 hour glucose and mean amplitude of glycemic excursions, 2 indexes of glycemic variability, were significantly decreased in patients receiving DPP-4 inhibitors but were unchanged in those not receiving these drugs. Conclusions: Add-on therapy with tofogliflozin to DPP-4 inhibitors acutely reduces 24-hour glucose levels and improves glycemic variability in patients with type 2 diabetes.
\end{abstract}

\section{Introduction}

Sodium glucose co-transporter 2 (SGLT2) inhibitors improve glycemic control in people with type 2 diabetes by increasing urinary glucose excretion; additional benefits are body weight loss and a low risk of hypoglycemia (1). Furthermore, several large-scale clinical trials of SGLT2 inhibitors have shown that these drugs have beneficial effects on cardiovascular outcomes - including hospitalization for heart failure and cardiovascular death - and renal outcomes in high-risk patients and that these effects appear to be independent of the glucose-lowering efficacy of these drugs (2-4).

SGLT2 inhibitors have been reported to increase plasma glucagon concentration and endogenous glucose production (EGP) in patients with type 2 diabetes $(5,6)$. Ferrannini et al demonstrated that acute dosing (ie, a single tablet) of empagliflozin, an SGLT2 inhibitor, increases both fasting and postprandial rates of EGP in patients with type 2 diabetes (5). The increase in EGP after treatment with SGLT2 inhibitors may be attributed partly to an elevated plasma glucagon level. The reduction in plasma glucose concentration expected with SGLT2 inhibitors may be partially offset by a concomitant increase in EGP through a compensatory mechanism caused by declining blood glucose or glucosuria $(5,6)$. 
In contrast, dipeptidyl peptidase (DPP)-4 inhibitors, incretin-based drugs, suppress EGP by stimulating insulin secretion and inhibiting glucagon secretion by enhancing glucagon-like peptide-1 (GLP-1) (7, 8). DPP-4 inhibitors may antagonize the compensatory increase in EGP induced by SGLT2 inhibitors. Therefore, we hypothesized that the increase in EGP after administration of SGLT2 inhibitors may be attenuated in patients receiving DPP-4 inhibitors and that, consequently, the glucose-lowering effects of SGLT2 inhibitors may be stronger in patients receiving DPP-4 inhibitors than in those not receiving them. To study this hypothesis, we investigated the acute effect of addition of tofogliflozin, an SGLT2 inhibitor, on 24-hour glucose levels and glycemic variability evaluated by continuous glucose monitoring (CGM) in patients with type 2 diabetes receiving or not receiving DPP-4 inhibitors.

\section{Subjects and Methods}

We studied 17 patients with type 2 diabetes who were hospitalized for glycemic control at the Dokkyo Medical University Hospital (Mibu, Tochigi, Japan). Patients were eligible for enrollment if they had type 2 diabetes, were at least 20 years old and had a glycated hemoglobin (HbA1c) level of $6.0 \%$ to $12.0 \%$ on stable therapy with 1 to 3 oral antidiabetic drugs with or without insulin for at least 3 months. During hospitalization, all patients received an optimal diet therapy (25 to $30 \mathrm{kcal} / \mathrm{kg}$ of ideal body weight; $50 \%$ carbohydrate, $20 \%$ protein, and $30 \%$ fat). Tofogliflozin $20 \mathrm{mg}$ /day was administered to 10 patients who were receiving DPP-4 inhibitors and to 7 patients who were not receiving these drugs.

During the last week of hospitalization, a CGM device (iPro2; Medtronic MiniMed. Inc., Northridge, CA, USA) was attached to each patient for 1 week. During the study period, no other anti-diabetic drugs were added and the dose of antidiabetic drugs and insulin remained unchanged. The starting day of CGM was defined as day 1 . On day 4 , treatment with tofogliflozin $20 \mathrm{mg} /$ day was started. We compared the mean values of CGM parameters on day 2 and 3 (ie, before starting treatment with tofogliflozin) with those on day 5 and 6 (ie, after staring treatment with tofogliflozin). As indexes of glycemic variability, the 24-hour mean glucose level, standard deviation (SD) of the 24-hour glucose level, mean amplitude of glycemic excursions (MAGE), and mean of postprandial glucose excursion (MPPGE) were calculated from CGM. We evaluated postprandial glucose within 1 to 3 hours after each meal and the time in range as the percent time with a glucose level between 70 and $180 \mathrm{mg} / \mathrm{dL}$. Time below range was defined as the percent of time with a glucose level less than $70 \mathrm{mg} / \mathrm{dL}$, and time above range, as the percent of time with a glucose level above $180 \mathrm{mg} / \mathrm{dL}$.

All participants gave written informed consent to participate in the study, which was approved by the Institutional Review Board of Dokkyo Medical University (approval no. 28150). The study was registered with the University Hospital Medical Information Network Clinical Trials Registry (UMIN000025454).

\section{Statistical analysis}

Results were expressed as the mean (SD) or the median and interquartile range. Differences between groups were analyzed by Student's paired $t$ test or unpaired $t$ test, and differences in nonparametric data were assessed by Wilcoxon's matched-pairs test or the Mann-Whitney U test. A $P$ value of less than 0.05 was considered statistically significant.

\section{Results}

As shown in Table 1, the overall characteristics of the two groups of patients were well matched at baseline. There were also no significant differences in indexes derived from CGM between the groups at baseline.

CGM showed that 24-hour mean glucose and postprandial glucose after each meal decreased significantly after treatment with tofogliflozin in patients receiving or not receiving DPP-4 inhibitors (Fig. 1A and B, and Table 2). Time in range increased significantly after treatment in both the group receiving DPP-4 inhibitors (from $54.9 \% \pm 27.8 \%$ to $78.2 \% \pm 22.2 \%$, respectively; $P=0.0120$ ) and the group not receiving them (from $65.5 \% \pm 33.9 \%$ to $83.9 \% \pm 20.2 \%$, respectively; $P=0.0276$ ), and time above range significantly decreased in both groups (Table 2). 
After treatment with tofogliflozin, the SD of 24-hour glucose significantly decreased in the group receiving DPP-4 inhibitors (from $40.80 \pm 17.89 \mathrm{mg} / \mathrm{dL}$ to $29.70 \pm 10.23 \mathrm{mg} / \mathrm{dL}, P=0.0108$; Table 2) but did not significantly change in the group not receiving DPP-4 inhibitors $(\mathrm{P}=0.1028)$. In patients receiving DPP-4 inhibitors, MAGE was significantly reduced (from $98.8 \pm 41.6 \mathrm{mg} / \mathrm{dL}$ to $70.9 \pm 29.3 \mathrm{mg} / \mathrm{dL}, P=0.0066$ ), as was MPPGE (from $77.2 \pm 41.8 \mathrm{mg} / \mathrm{dL}$ to $63.8 \pm 32.1 \mathrm{mg} / \mathrm{dL}, \mathrm{P}=0.0378$ ); however, both these indexes of glycemic variability were unchanged in patients not receiving DPP-4 inhibitors (Table 2).

\section{Discussion}

In the present study, we found that tofogliflozin acutely decreased 24-hour mean glucose levels and postprandial glucose levels after each meal and increased time in range in patients with type 2 diabetes, irrespective of treatment with DPP-4 inhibitors. These findings are in agreement with previous studies, including ours (5, 9-11). In a previous study with CGM, we also demonstrated that acute dosing with a single tablet of canagliflozin, another SGLT2 inhibitor, caused a significant reduction in 24-hour mean glucose levels (10). Another study also found that an SGLT2 inhibitor lowered glucose levels from 2 hours after a single dose and improved glycemic variability within 1 week of treatment (11). The finding that tofogliflozin significantly reduced postprandial glucose after each meal is in accordance with other CGM studies on the SGLT2 inhibitor class $(5,9-12)$. In the present study, we could confirm by CGM that tofogliflozin rapidly lowers blood glucose levels.

This is the first study to compare the acute effects of a SGLT2 inhibitor on the 24-hour glucose profile and glycemic variability evaluated by CGM between patients receiving and those not receiving DPP-4 inhibitors. CGM revealed that the SD of 24-hour glucose levels, an index of glycemic variability, was significantly reduced in patients receiving DPP-4 inhibitors but was unchanged in those not receiving these drugs. Moreover, both MAGE and MPPGE, other indexes of glycemic variability, were significantly reduced only in patients receiving DPP-4 inhibitors. Thus, SGLT2 inhibitors may improve glycemic variability more strongly as an add-on treatment in patients receiving DPP-4 inhibitors than in patients not receiving DPP-4 inhibitors. Several studies reported that glucose fluctuations have a more specific triggering effect on oxidative stress than chronic sustained hyperglycemia (13-14). We speculate that improvement of glycemic variability by tofogliflozin may suppress development of cardiovascular events in patients with type 2 diabetes, especially those receiving DPP-4 inhibitors.

The mechanisms by which add-on therapy with tofogliflozin reduces glycemic variability only in patents receiving DPP-4 inhibitors remains unclear. One possible explanation is that DPP-4 inhibitors, which inhibit glucagon secretion and promote insulin secretion by enhancing the effects of the incretin hormone GLP-1, may potentially attenuate the increase in hepatic glucose production induced by SGLT2 inhibitors $(5,6)$. In a previous study, we demonstrated that, during a meal test, plasma glucagon level was significantly reduced 30 minutes after treatment with teneligliptin (a DPP-4 inhibitor) compared with baseline (15). Enhancement of GLP-1 action by DPP-4 inhibitors may increase insulin secretion and suppress glucagon release in a glucosedependent manner, leading to a decrease in postprandial glucose levels. Adding SGLT2 inhibitors to existing DPP-4 inhibitors could suppress EGP secondary to excess excretion of glucose into urine because treatment with DPP-4 inhibitors can offset SGLT2-induced EGP by inhibiting glucagon secretion and simulating insulin secretion. A previous study with CGM demonstrated that add-on therapy with canagliflozin did not increase fasting or postprandial plasma glucagon in patients with type 2 diabetes receiving teneligliptin (16). Taken together, the findings indicate that a combination of SGLT2 inhibitors and DPP-4 inhibitors may be an effective treatment for patients with type 2 diabetes because of the complementary pharmacological effects of these drugs, ie, because of the opposite mechanisms of action of DPP-4 inhibitors and SGLT2 inhibitors on EGP, and because both medications have a fairly low risk of hypoglycemia (17).

The present study clearly has some limitations. First, the number of participants was small, so the results need to be confirmed in a larger study. Second, we did not measure plasma glucagon or insulin levels during CGM, so we could not prove that DPP-4 inhibitors counteract SGLT2-induced EGP by inhibiting glucagon secretion and simulating insulin secretion. 
In conclusion, add-on therapy of tofogliflozin to DPP-4 inhibitors acutely reduces 24-hour mean glucose levels and improves glycemic variability in patients with type 2 diabetes.

\section{Declaration of conflicting interests}

The author(s) declared no potential conflicts of interest with respect to the research, authorship and/or publication of this article.

\section{Funding}

The author(s) received no financial support for the research, authorship and/or publication of this article.

Author contributions: TI, SH, HK, HK, and SS contributed to the study design, data collection, and drafting of the manuscript; TT, TJ, and IU contributed to the discussion and reviewed the manuscript; IU reviewed and edited the manuscript; and TI and YA researched the data and wrote, reviewed, and edited the manuscript.

\section{References}

1. Tahrani AA, Barnett AH, Bailey CJ. SGLT2 inhibitors in management of diabetes. Lancet Diabetes Endocrinol. 2013; 1:140-51.

2. Zinman B, Wanner C, Lachin JM, Fitchett D, Bluhmki E, Hantel S, Mattheus M, Devins T, Johansen OE, Woerle HJ, Broedl UC, Inzucchi SE; EMPA-REG OUTCOME Investigators. Empagliflozin, Cardiovascular Outcomes, and Mortality in Type 2 Diabetes. N Engl J Med. 2015; 373(22):2117-28.

3. Neal B, Perkovic V, Mahaffey KW, de Zeeuw D, Fulcher G, Erondu N, Shaw W, Law G, Desai M, Matthews DR; CANVAS Program Collaborative Group. Canagliflozin and Cardiovascular and Renal Events in Type 2 Diabetes. N Engl J Med. 2017;377(7):644-657.

4. Wiviott SD, Raz I, Bonaca MP, Mosenzon O, Kato ET, Cahn A, Silverman MG, Zelniker TA, Kuder JF, Murphy SA, Bhatt DL, Leiter LA, McGuire DK, Wilding JPH, Ruff CT, Gause-Nilsson IAM, Fredriksson M, Johansson PA, Langkilde AM, Sabatine MS; DECLARE-TIMI 58 Investigators. Dapagliflozin and Cardiovascular Outcomes in Type 2 Diabetes. N Engl J Med. 2019;380(4):347-357.

5. Ferrannini E, Muscelli E, Frascerra S, Baldi S, Mari A, Heise T, Broedl UC, Woerle HJ. Metabolic response to sodium-glucose cotransporter 2 inhibition in type 2 diabetic patients. J Clin Invest. 2014;124(2):499-508.

6. Merovci A, Solis-Herrera C, Daniele G, Eldor R, Fiorentino TV, Tripathy D, Xiong J, Perez Z, Norton L, Abdul-Ghani MA, DeFronzo RA. Dapagliflozin improves muscle insulin sensitivity but enhances endogenous glucose production. J Clin Invest. 2014;124(2):509-14.

7. Herman GA, Bergman A, Stevens C, Kotey P, Yi B, Zhao P, Dietrich B, Golor G, Schrodter A, Keymeulen B, Lasseter KC, Kipnes MS, Snyder K, Hilliard D, Tanen M, Cilissen C, De Smet M, de Lepeleire I, Van Dyck K, Wang AQ, Zeng W, Davies MJ, Tanaka W, Holst JJ, Deacon CF, Gottesdiener KM, Wagner JA. Effect of single oral doses of sitagliptin, a dipeptidyl peptidase-4 inhibitor, on incretin and plasma glucose levels after an oral glucose tolerance test in patients with type 2 diabetes. J Clin Endocrinol Metab. 2006;91(11):4612-9.

8. Balas B, Baig MR, Watson C, Dunning BE, Ligueros-Saylan M, Wang Y, He YL, Darland C, Holst JJ, Deacon CF, Cusi K, Mari A, Foley JE, DeFronzo RA. The dipeptidyl peptidase IV inhibitor vildagliptin suppresses endogenous glucose production and enhances islet function after single-dose administration in type 2 diabetic patients. J Clin Endocrinol Metab. 2007;92(4):1249-55.

9. Yamada K, Nakayama H, Yoshinobu S, Kawano S, Tsuruta M, Nohara M, Hasuo R, Akasu S, Tokubuchi I, Wada N, Hirao S, Iwata S, Kaku H, Tajiri Y. Effects of a sodium glucose co-transporter 2 selective inhibitor, ipragliflozin, on the diurnal profile of plasma glucose in patients with type 2 diabetes: A study using continuous glucose monitoring. J Diabetes Investig. 2015;6(6):699-707

10. Matsumura M, Nakatani Y, Tanka S, Aoki C, Sagara M, Yanagi K, Suzuki K, Aso Y. Efficacy of Additional Canagliflozin Administration to Type 2 Diabetes Patients Receiving Insulin Therapy: Examination of Diurnal Glycemic Patterns Using Continuous Glucose Monitoring (CGM). Diabetes Ther. 2017;8(4):821-827 
11. Torimoto K, Okada Y, Koikawa K, Tanaka Y. Early effects of sodium-glucose co-transporter 2 inhibitors in type 2 diabetes: study based on continuous glucose monitoring. Diabetol Metab Syndr. 2017 Aug $4 ; 9: 60$.

12. Nishimura R, Tanaka Y, Koiwai K, Inoue K, Hach T, Salsali A, Lund SS, Broedl UC. Effect of empagliflozin monotherapy on postprandial glucose and 24-hour glucose variability in Japanese patients with type 2 diabetes mellitus: a randomized, double-blind, placebo-controlled, 4-week study. Cardiovasc Diabetol. 2015 Jan 30;14:11.

13. Monnier L, Mas E, Ginet C, Michel F, Villon L, Cristol JP, Colette C. Activation of oxidative stress by acute glucose fluctuations compared with sustained chronic hyperglycemia in patients with type 2 diabetes. JAMA. 2006;295(14):1681-7.

14. Ceriello A, Esposito K, Piconi L, Ihnat MA, Thorpe JE, Testa R, Boemi M, Giugliano D. Oscillating glucose is more deleterious to endothelial function and oxidative stress than mean glucose in normal and type 2 diabetic patients. Diabetes. 2008;57(5):1349-54.

15. Aso Y, Kase M, Sagara M, Sakurai S, Iijima T, Tomaru T, Jojima T, Usui I. Teneligliptin, a DPP4 Inhibitor, Decreases Plasma Levels of Inflammatory Chemokines During a Standard Meal Test in Patients With Type 2 Diabetes. Am J Med Sci. 2020;360(3):261-267.

16. Noda T, Ebihara E, Ueno H, Sadohara K, Tanaka Y, Nagatomo Y, Murakami Y, Yonamine S, Tsuchimochi W, Sakoda H, Yamaguchi H, Nakazato M. Concurrent Use of Teneligliptin and Canagliflozin Improves Glycemic Control with Beneficial Effects on Plasma Glucagon and Glucagon-Like Peptide-1: A Single-Arm Study. Diabetes Ther. 2019;10(5):1835-1846.

17. Sharma MD. Potential for combination of dipeptidyl peptidase-4 inhibitors and sodium-glucose cotransporter-2 inhibitors for the treatment of type 2 diabetes. Diabetes Obes Metab. 2015;17(7):616-21.

\section{Figure legends}

Fig.1

The average glucose levels before and after treatment with tofogliflozin $20 \mathrm{mg} /$ day in patients with type 2 diabetes receiving (A) or not receiving dipeptidyl peptidase-4 (DPP-4) inhibitors (B).

\section{Hosted file}

Figure.pptx available at https://authorea.com/users/308349/articles/524548-acute-effectof-add-on-therapy-with-tofogliflozin-a-sodium-glucose-co-transporter-2-inhibitoron-24-hour-glucose-profile-and-glycemic-variability-evaluated-by-continuous-glucosemonitoring-in-patients-with-type-2-diabetes-receiving-dipeptidyl-peptidase-4-inhibitors

\section{Hosted file}

Table 1 Patient characetristics with and without DPP-4i.doc available at https://authorea. com/users/308349/articles/524548-acute-effect-of-add-on-therapy-with-tofogliflozina-sodium-glucose-co-transporter-2-inhibitor-on-24-hour-glucose-profile-and-glycemicvariability-evaluated-by-continuous-glucose-monitoring-in-patients-with-type-2-diabetesreceiving-dipeptidyl-peptidase-4-inhibitors

\section{Hosted file}

Table 2 Changes in CGM parameters after treatment with tofogliflozin.doc available at https://authorea.com/users/308349/articles/524548-acute-effect-of-add-on-therapy-withtofogliflozin-a-sodium-glucose-co-transporter-2-inhibitor-on-24-hour-glucose-profileand-glycemic-variability-evaluated-by-continuous-glucose-monitoring-in-patients-withtype-2-diabetes-receiving-dipeptidyl-peptidase-4-inhibitors 